\title{
As novas relações entre o urbano e o rural: o caso dos agricultores familiares feirantes de Igrejinha/RS
}

The new relations between the urban and the rural: the case of small farmers traders of Igrejinha/RS

\section{Jorge Amaral de Moraes}

Faculdades Integradas de Taquara - FACCAT - Taquara - Rio Grande do Sul - Brasil

\section{Darlã de Alves}

Faculdades Integradas de Taquara - FACCAT - Taquara - Rio Grande do Sul - Brasil

\section{Alexandre Aloys Matte Júnior}

Faculdades Integradas de Taquara - FACCAT - Taquara - Rio Grande do Sul - Brasil

Resumo: O objetivo principal deste artigo é analisar os efeitos das mudanças nas organizações produtivas urbanas sobre as características da produção e da comercialização de produtos agrícolas e sobre o nível de renda dos agricultores familiares do município de Igrejinha-RS. O artigo utiliza como metodologia o estudo de caso, amparado por uma revisão bibliográfica, uma pesquisa documental realizada no Sindicato dos Trabalhadores Rurais e na Prefeitura Municipal de Igrejinha e a aplicação de um questionário para 12 produtores rurais participantes das Feiras de Produtores. Estes comercializam seus produtos com a população local de Igrejinha, em vários pontos da cidade. Os resultados apontam a predominância de sistemas de produção de base familiar, contando com propriedades médias de nove hectares. Verificou-se que há uma grande variedade de cultivos, mas predominando a olericultura. Ainda, através da aplicação dos questionários, evidenciou-se a influência direta do meio urbano sobre o rural no município, impactando de forma determinante o nível de produção e renda dos pequenos agricultores. Por sua vez, estes são obrigados a elaborar diferentes estratégias para viabilizar a continuidade de sua produção, como a redução de preços e a diversificação, visando o aumento da competitividade, e a diminuição da produção, buscando evitar eventuais sobras.

Palavras-chave: Desenvolvimento rural. Cadeias curtas. Agricultura familiar.

\begin{abstract}
The main objective of this article is to analyze the effects of changes in urban productive organizations on the characteristics of production and commercialization of agricultural products and on the level of income of family farmers in the municipality of Igrejinha-RS. The article uses as methodology the work is a case study, supported by a bibliographical review, a documentary research carried out at the Sindicato dos Trabalhadores Rurais and at the Municipality of Igrejinha and the application of a questionnaire to 12 Rural Producers participating in the Producer Fairs. They market their products with the local population of Igrejinha, in various parts of the city. The results indicate the predominance of family-based production systems, with average properties of nine hectares. It was verified that there is a great variety of cultures, but predominating vegetable produtction. Also, through the application of the questionnaires, the direct influence of the urban environment on the rural in the municipality was evidenced, impacting in a determinant way the level of production and income of the small farmers. In turn, they are obliged to elaborate different strategies to enable the continuity of their production, such as price reduction and diversification, aiming at increasing competitiveness, and reducing production, in order to avoid eventual leftovers.
\end{abstract}

Keywords: Rural development. Short chains. Family farming. 


\section{Introdução}

A cidade de Igrejinha/RS tem sua economia baseada essencialmente na indústria calçadista. Embora disponha de atividades diversificadas, geradas por indústrias de pequeno e médio porte e pelo comércio varejista, a maior parcela de renda e dos empregos são gerados pelo setor coureirocalçadista, contando com grandes expoentes desse setor. O setor calçadista representa um importante diferencial na economia brasileira e, principalmente, na de Igrejinha.

Conforme dados apresentados pela APICCAPS - Associação Portuguesa das Indústrias de Calçado, Componentes, Artigos de Pele e seus Sucedâneos - (2014), em seu anuário com dados referentes à 2011, o Brasil ocupa a terceira posição no ranking dos maiores produtores de calçados no mundo, em um segmento amplamente dominado pelos países asiáticos, principalmente a China. A entidade também aponta, dentro desse panorama, o Rio Grande do Sul como o terceiro maior exportador de calçados de nosso país, representando $13,4 \%$ do número de pares remetidos ao exterior em 2013. Porém, esta exportação gera a maior renda do setor, entre todos os estados brasileiros, totalizando US\$ 387,06 milhões, em virtude do maior valor agregado dos produtos gaúchos exportados.

As dificuldades enfrentadas pelo setor nos últimos anos, decorrentes principalmente da globalização e da concorrência em nível mundial no campo das exportações, em grande parte devido aos baixos custos de produção conquistados pelos países asiáticos, tiveram um forte impacto no setor calçadista da região dos Vales dos Sinos e do Paranhana, resultando no fechamento de empresas e extinção de postos de trabalho (MATTE JR, MORAIS, SELLITO; 2016). Segundo Calandro e Campos (2013), as maiores perdas ocorreram nos municípios onde a estrutura industrial era concentrada na atividade coureiro calçadista, enfrentando graves problemas em relação à crise no setor, resultando em desemprego e expressiva perda de participação no PIB do Rio Grande do Sul.
Dentro desse panorama, em uma região como - Vale do Paranhana, com predominância da atividade industrial calçadista, o fechamento de fábricas e o aumento do índice de desemprego acaba desacelerando a economia local e afetando diretamente o comércio e o fluxo de produtos no mercado. Essa situação também tem impactos importantes sobre o meio rural e as suas atividades produtivas. A maior parte dos produtores rurais de Igrejinha-RS é de base familiar, que atualmente comercializam os seus produtos em feiras organizadas em diversos bairros da cidade, onde encontram importante oportunidade de ampliar sua renda através da comercialização da sua produção. Com o aumento da taxa de desemprego, existe a possibilidade de que isso tenha causado impactos diretos na produção, comercialização e na renda dos agricultores familiares do município.

Tendo isto em vista, este artigo tem como objetivo analisar os efeitos das recentes mudanças nas organizações produtivas urbanas sobre a produção e a comercialização agroalimentar e o nível de renda dos agricultores familiares do município de Igrejinha-RS. Mais especificamente, busca-se descrever a situação atual da estrutura produtiva da agricultura familiar municipal, analisar os efeitos das mudanças no nível de produção e emprego das indústrias do município sobre a renda e a comercialização dos agricultores familiares e as estratégias adotadas por esses agricultores visando amenizar eventuais efeitos negativos dessas mudanças sobre as suas atividades produtivas.

Assim, a relevância deste estudo evidencia-se pela importância do papel desempenhado pela agricultura familiar no desenvolvimento socioeconômico do território em que está inserida e do Rio Grande do Sul. Conforme Gobbi e Pessoa (2009), a agricultura familiar passou a receber mais atenção a partir da década de 1990, ressaltando-se a sua influência na geração de renda, emprego e melhorias da população rural. Wagner, Gehlen e Wiest (2004) defendem a sua importância por meio da diversificação de fontes de renda, já que, em sua maioria, as propriedades contam com outras 
atividades agropecuárias e de serviços, o que dá amparo para que permaneçam nesse modelo e no meio rural.

Com relação aos procedimentos metodológicos, a pesquisa foi dividida em duas partes. A primeira parte da coleta de informações foi concretizada a partir de uma pesquisa documental, buscando informações em órgãos públicos e sindicais (como registros e base de dados não acessíveis ao público em geral), realizada no Sindicato dos Trabalhadores Rurais e na Prefeitura Municipal de Igrejinha. Buscou-se informações complementares no IBGE sobre o município de Igrejinha e relacionadas ao meio rural e seus produtores, bem como possíveis detalhes sobre os projetos destinados a essa classe. A segunda parte da coleta de dados ocorreu através de visitas às feiras de produtores e aplicação de um questionário aos chefes de cada família, buscando caracterizar esses produtores e avaliar os possíveis efeitos do meio urbano sobre o rural. O questionário possui 13 questões, tanto qualitativas (semiestruturadas) quanto quantitativas (fechadas), sendo aplicado a 12 chefes de família. Analisando-se as respostas, faz-se necessário o uso da estatística descritiva para melhor organizar as informações e apresentá-las de forma mais dinâmica.

Além desta introdução, este artigo está organizado da forma descrita a seguir. Na próxima seção apresentam-se os conceitos de agricultura familiar e a importância da relação desta com os mercados agroalimentares locais, necessários para o embasamento do estudo. A seção três apresenta a caracterização do município de Igrejinha e da região onde o mesmo está inserido. Já na seção quatro são apresentados os resultados obtidos na análise dos dados realizada. Por fim, apresentam-se as considerações finais resultantes do desenvolvimento da pesquisa.

\section{As relações urbano-rurais e a agricultura familiar}

No Brasil, a partir da década de 1990, começaram a emergir novas abordagens analíticas nos estudos e políticas públicas direcionadas para o desenvolvimento rural. As principais causas para isso foram as transformações socioeconômicas e políticas, a incorporação da noção de sustentabilidade ambiental, uma nova interpretação do papel do rural no desenvolvimento regional e a emergência da perspectiva territorial do desenvolvimento rural (SCHNEIDER, 2003). De acordo com esse autor, foi nesse período que a noção de agricultura familiar se firmou como uma categoria política e foi assimilada por estudiosos e formuladores de políticas. E, assim, um dos temas que mais se destacou no debate sobre o desenvolvimento rural no Brasil foi o da agricultura familiar e de seu potencial como modelo socioeconômico e produtivo para a sociedade brasileira.

As novas perspectivas de estudo do desenvolvimento regional-rural vêm substituindo a visão tradicional baseada na dicotomia rural-urbana, que confundia o rural com o agrícola, por uma visão sobre o mundo rural baseada na possibilidade de os territórios rurais incluírem também as pequenas cidades do "interior". Assim, seriam possíveis novas alternativas de renda e emprego rural e diversas outras formas de melhoria na qualidade de vida da sua população. Isto é de grande relevância para o estudo de regiões com muitos municípios pequenos e/ou com grande contingente de população rural, como é o caso da região objeto deste estudo.

No debate brasileiro dos últimos anos verificase uma mudança de visão nas novas abordagens utilizadas para compreender o papel do "rural" no desenvolvimento regional do país. Essas novas abordagens de estudo do desenvolvimento territorial rural tendem a substituir a visão tradicional que relacionava o rural com atraso e como sinônimo de agrícola e, por outro lado, o urbano com moderno, industrial e com o setor de serviços.

$\mathrm{Na}$ tentativa de estabelecer uma ponte hierárquica entre os significados de rural e local nos programas de desenvolvimento, Wanderley (2001) argumenta que os programas de desenvolvimento local, em vez de substituir o desenvolvimento rural, incorporam este como parte integrante, sem anular as 
particularidades de cada um. Acontece onde a diversidade e a proximidade são fontes de integração e cooperação e, ao mesmo tempo, de tensões e conflitos, configurando uma rede de relações recíprocas e complexas. A autora conclui afirmando que se a vida local é o resultado do encontro entre o rural e o urbano, o desenvolvimento local, entendido como o processo de valorização do potencial econômico, social e cultural dessa sociedade, não pode supor o fim do rural (WANDERLEY, 2001).

Essas novas perspectivas sobre o mundo rural se apoiam em argumentos que abrem a possibilidade de o território rural oferecer alternativas de emprego e renda. Mas, para oferecer isso, o território rural tem que utilizar o seu potencial local e aproveitar as suas características históricas e culturais particulares, como a presença de agricultores familiares, e, por outro lado, estar integrado socioeconomicamente ao seu entorno e com o exterior. Estes são os contornos que poderão levar a uma nova ruralidade e contribuir para o desenvolvimento local dos territórios rurais.

\subsection{Agricultura familiar}

Conforme dados do último Censo Agropecuário do IBGE (2006), a agricultura familiar é responsável por $70 \%$ da produção de alimentos no Brasil, representando $10 \%$ do PIB nacional e $75 \%$ da mão de obra trabalhadora no campo. No entanto, ainda há um importante segmento da agricultura familiar brasileira que não consegue se sustentar economicamente devido aos mecanismos de comercialização da produção e dos insumos, vinculação ao mercado, quando, muitas vezes, esta ocorre por meio de intermediários ou comerciantes regionais-locais, o que reduz as margens de escolha na comercialização e as possibilidades de acesso ao crédito e à informação.

No Brasil, o conceito de agricultura familiar é relativamente recente, uma vez que esteve em constante evolução e recebeu diversas conotações. Como características da agricultura familiar, Neto e Basso (2005), Couto (2013) e Gobbi e Pessoa (2009) definem que esta caracteriza-se pela família ser proprietária da terra e dos meios de produção, assumindo a maior parte do trabalho no seu estabelecimento produtivo, assegurando a alimentação da família através do próprio processo de diversificação produtiva. O tamanho da propriedade é estabelecido pelo que a família pode explorar, com base em seu próprio trabalho, associado a tecnologias e meios dos quais dispõe (NETO, BASSO, 2005). Schneider (2001) afirma que esta pode ser entendida como um grupo social que compartilha um mesmo espaço (não necessariamente uma mesma habitação) e possui em comum a propriedade de um pedaço de terra, ligados por laços de parentesco entre si, podendo pertencer a esse coletivo membros não consanguíneos. O coletivo, a família, organiza a produção e gerencia a propriedade, estabelecendo estratégias individuais e coletivas que visem garantir a reprodução social. Além disso, Denardi (2001) frisa o fato de a gestão da propriedade, como por exemplo dos meios produtivos e fluxos financeiros, ser realizada predominantemente pelo próprio núcleo familiar, podendo contar ou não com a terceirização de atividades.

A conquista de mercado por parte dos produtores de base familiar gera impactos favoráveis, principalmente, às regiões do interior do país, evitando o êxodo rural através da geração de trabalho e renda, tornando-se um instrumento de desenvolvimento social (GOBBI, PESSOA, 2009). Neto e Basso (2005) afirmam que é possível enxergar a diferença proporcionada pela geração e divisão de renda em áreas com predominância da pecuária e agricultura familiar, onde também ocorre um fácil acesso à terra, resultando na ampliação da renda e em melhores condições à população da região em que está inserida.

Para Abramovay e Veiga (1999), a agricultura familiar exerce papel fundamental no que diz respeito à segurança alimentar e à ocupação da população rural. Além disso, o portal da Embrapa - Empresa Brasileira de Pesquisa Agropecuária (2016) - cita que no Brasil o setor engloba 4,3 milhões de unidades produtivas, o que representa $84 \%$ do total, e 14 milhões de pessoas ocupadas, representando cerca 
de $74 \%$ do total das ocupações, distribuídas em 80.250 .453 hectares (25\% da área total). A produção que resulta da agricultura familiar se destina basicamente às populações urbanas locais, garantindo a sua segurança alimentar e nutricional (Embrapa, 2016).

Como forma de minimizar impactos externos do mercado e promover uma forma mais organizada de participação no mercado, Costa et al (2015) destacam a organização dos produtores, principalmente os que utilizam base familiar de produção, através de sindicatos e, em diversos casos, cooperativas, centralizando a produção e proporcionando maior poder de venda e negociação junto a compradores e vendedores de insumos, necessários ao manejo do rebanho.

A situação atual da agricultura familiar brasileira resulta de um processo histórico, passando por diversas transformações, ficando, por um bom tempo, a margem dos investimentos governamentais, preocupados em direcionar esforços aos grandes latifúndios e à produção de bens para exportação. De igual forma, a modernização da agricultura brasileira nas décadas de 60 e 70 colaborou com o êxodo rural, uma vez que privilegiou as commodities destinadas ao mercado externo (MATTEI, 2014). Após a atuação de movimentos sociais ligados ao campo, liderados principalmente pela Confederação Nacional dos Trabalhadores da Agricultura (CONTAG), a agricultura familiar emergiu na década de 1990, passando a fazer parte da pauta de esforços governamentais. O governo reconhece o potencial e capacidade da agricultura familiar de se adaptar a situações diversas e contribuir para o desenvolvimento econômico, sendo que os aspectos econômicos, sociais, ecológicos e culturas devem ser levados em conta na busca de soluções não excludentes e visando o desenvolvimento local (CARNEIRO, 1997).

Além disso, Veiga (2006) e Favareto (2006) sinalizam uma "nova ruralidade", caracterizada pela conservação da biodiversidade e aproveitamento econômico de suas paisagens e espaços naturais através das diversas formas de turismo, impulsionadas pela grande procura do ecoturismo. Assim, em vez de desaparecer, como expressavam teorias sobre o futuro da relação entre rural-urbano, o ambiente rural se integra por meio tanto da unificação dos diferentes mercados (de trabalho, de produtos e serviços, e de bens simbólicos) como também por meio da criação de instituições que regulam as formas de uso social destes espaços. Tais constatações trazem a ideia do novo rural, valorizado pelos indivíduos principalmente por contar com traços intocados da natureza, refletindo assim na produção de suas propriedades, uma vez que se tornam cada vez mais valiosas à qualidade da vida e bem-estar (VEIGA, 2006).

\subsection{0 acesso aos mercados agroalimentares locais}

De maneira geral, a maior dificuldade dos agricultores familiares encontra-se justamente na comercialização. Segundo Abramovay e Veiga (1999), o principal problema para que a agricultura familiar se converta na base do desenvolvimento rural está em conseguir formas de participação em mercados dinâmicos, competitivos e exigentes em inovações, pois existe uma tendência, no médio e longo prazo, de uma consistente redução de preços da produção agrícola e da renda bruta. De acordo com o mesmo autor, a solução poderia vir de uma mudança decisiva nas formas de organização dos produtores familiares, já que é na construção de novos mercados que se concentra o mais importante desafio do desenvolvimento rural. Sabe-se que, mesmo nos mercados convencionais de produtos agrícolas, há um espaço significativo que pode ser ocupado pela agricultura familiar cujo desempenho, entretanto, vai depender fundamentalmente de sua capacidade de organização local e apoio das instituições públicas e privadas para facilitar a sua articulação com as dinâmicas socioeconômicas de desenvolvimento dos territórios rurais.

A criação de estratégias, individuais e coletivas, que possibilitem a melhoria das condições de acesso aos mercados e de agregação de valor à 
produção agropecuária tornam-se um dos maiores desafios enfrentados pelos agricultores familiares. $\mathrm{Na}$ comercialização da produção, o desafio para o agricultor familiar é superar a pressão pela especialização e pelo aumento da escala para reduzir custos. Com a especialização em um único cultivo, o agricultor familiar perderia as vantagens da produção diversificada, se tornando vulnerável às oscilações de preços e às eventuais quedas de produção. A comercialização na agricultura familiar está baseada na diversificação da produção, e não na escala, uma das principais diferenças da agricultura patronal ou de grande escala.

Outro desafio para a agricultura familiar, como forma de viabilizar a produção, é a necessidade de industrialização e de agregação de valor, realizadas pela transformação ou beneficiamento dessa produção. Com a industrialização e a agregação de valor fazendo parte do processo produtivo da agricultura familiar, seria possível garantir a soberania alimentar da população e a possibilidade de controle de diversos segmentos das cadeias produtivas, podendo incluir também a distribuição e a produção de alguns insumos. Dessa forma, verifica-se uma mudança do papel da agricultura familiar, que passa da simples produção agrícola para a industrialização da matéria-prima.

A agricultura familiar tem como característica a diversidade, a dispersão e a heterogeneidade de produtores, dificultando o acesso aos mercados, já que grande parte deles não consegue manter escalas na comercialização de produtos mais homogêneos. Os agricultores familiares têm dificuldades de inserção nos mercados devido à quantidade produzida e ao baixo acesso aos serviços de assistência técnica e crédito. Porém, as cooperativas podem auxiliar no processo de transferência de tecnologias e informações nas cadeias produtivas e no ganho de escala na produção, facilitando as negociações com as grandes redes, a adoção dos padrões de produtos e sistemas de produção e a redução dos custos de transação.

A partir desse contexto, espera-se que a reprodução e a sustentabilidade socioeconômica da agricultura familiar de uma determinada região podem ser obtidas por meio de uma articulação com as dinâmicas de desenvolvimento dos territórios rurais. Isso pode ser realizado por meio do acesso aos mercados agroalimentares locais, mais próximos dos consumidores urbanos, estimulando a relação urbano-rural e o desenvolvimento regional.

\section{Características do município de Igrejinha e da região}

Procurando-se entender a dinâmica regional, torna-se importante caracterizar o meio em que o município de Igrejinha está situado. Utilizando como recorte a divisão dos Conselhos Regionais de Desenvolvimento (Coredes), o município de Igrejinha encontra-se dentro do Corede Paranhana-Encosta da Serra (Figura 1). Este Corede foi criado em 02 de junho de 1993 e formalizado em 1994, sendo composto inicialmente por onze municípios, até a exclusão do município de Picada Café que passou para o Corede das Hortênsias em 2002 (MORAIS, 2012). Possui uma população total estimada em 217.017 habitantes, dispostos em uma área de $1.732,8 \mathrm{~km}^{2}$, conforme dados da Fundação Estadual de Estatística - FEE (2016). A região do Corede em questão é dividida em duas microrregiões, sendo a composição da região do Paranhana, situada no vale do rio de mesmo nome, pelos municípios de Igrejinha, Parobé, Rolante, Riozinho, Taquara e Três Coroas, e na região da Encosta da Serra, onde engloba os municípios de Lindolfo Collor, Presidente Lucena, Santa Maria do Herval e Morro Reuter (MORAIS, 2012). Frisa-se a alta densidade demográfica do território deste Corede, que é de $121,3 \mathrm{~km} / \mathrm{km}^{2}$, enquanto que a densidade do estado do Rio Grande do Sul é de 38,1 hab/km² (FEE, 2016). 
Figura 1 - Conselhos Regionais de

Desenvolvimento - Coredes

\section{Conselhos Regionais de Desenvolvimento - (22 COREDEs - 1998)}

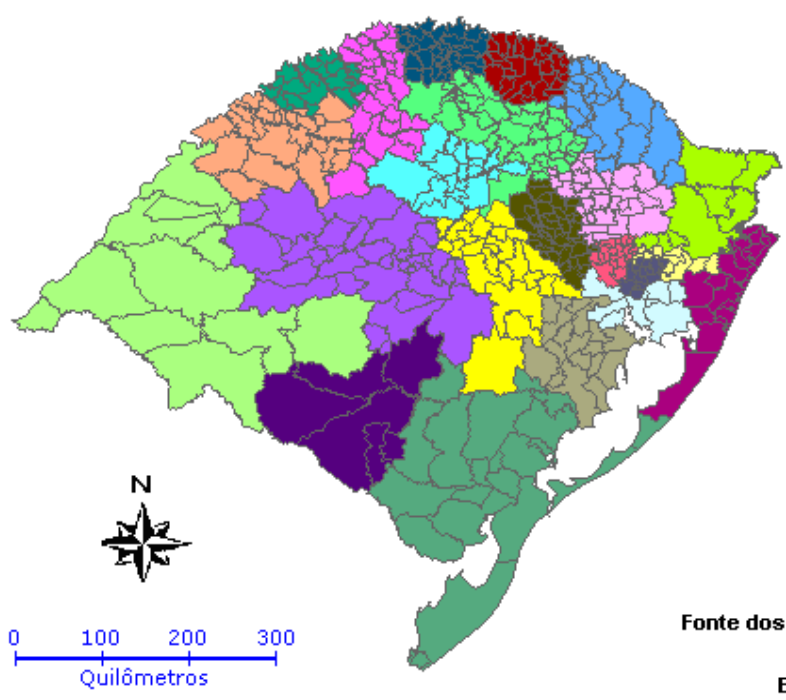

Fonte: FEE (2016)

Focando na Microrregião do Paranhana, Morais (2012) discorre sobre a colonização da região, que tem como característica básica a presença, inicialmente, de imigrantes alemães, que se identificavam principalmente com a produção agropecuária e a industrialização proporcionada pela produção calçadista, sendo essa uma marca da região. Galvão (1999) cita que os primeiros colonizadores eram provenientes da região do Hunsrück, na divisa com a França. O autor também salienta que em 1855 o vale já abrigava cerca de 400 famílias, dedicadas especialmente à agropecuária, mas que alguns alemães já possuíam conhecimento sobre o fabrico de sapatos, chinelos e tamancos, iniciando-se assim um pequeno nicho de produção de calçados sob encomenda. O autor ainda afirma que a partir da década de 1940, com a diminuição das exportações de piretro, a região passou a dedicar-se à fabricação de arreios e calçados.

Uma das principais características do setor coureiro-calçadista é a necessidade de um grande número de processos, o que acaba gerando a necessidade de um grande volume de mão de obra, já que diversas tarefas são praticamente artesanais (GALVÃO, 1999). Levando tais afirmações em consideração, Morais (2012) afirma que a partir da década de 1970 se observa um deslocamento populacional das zonas rurais para os centros urbanos, sendo que aproximadamente 68\% da população da região já estava residindo na zona urbana, o que proporcionou uma alavancagem no setor coureiro-calçadista, onde os moradores foram atraídos pela oferta de empregos e outros fatores, como educação, saúde e infraestrutura. No Quadro 1 verifica-se o tamanho da população urbana e rural, baseados em dados do Censo Demográfico de 2010, evidenciando a grande discrepância e o fenômeno de êxodo rural ocorrido desde a década de 1970.

Nota-se, através da visualização do Quadro 1, que a maior diferença entre a população urbana e a rural concentra-se nas cidades em que a atividade industrial desenvolveu-se intensamente, principalmente no âmbito coureiro-calçadista, citandose em especial as cidades de Igrejinha, Parobé e Três Coroas. Dessa forma, o setor industrial passou a ser o centro gerador de renda e a disponibilidade de mão de obra foi um fator motivador à instalação de um grande número de empresas na região. Galvão (1999) afirma que, em 1993, a participação da indústria no PIB da região já chegava a 63,73\%, enquanto a participação da indústria no estado do RS era de 36,54\%. Além disso, Morais (2012), apud 
Rumos 2015 (2012), cita o fato de o Corede Paranhana-Encosta da Serra possuir uma das menores extensões rodoviárias $(115,4 \mathrm{~km})$, o que facilita a proximidade entre empresas, fornecedores e entidades. Seus índices de acessibilidade são considerados ótimos, pois $90 \%$ da população encontra-se a menos de 5 quilômetros de uma rodovia pavimentada pertencente à rede rodoviária do Estado, no caso, as ERS 239 e ERS 115, na microrregião Paranhana, e a BR 116, na microrregião Encosta da Serra.

Quadro 1 - Dados demográficos do Corede Paranhana - Encosta da Serra

\begin{tabular}{|c|c|c|c|c|c|}
\hline \multirow[t]{2}{*}{ Município } & \multirow{2}{*}{$\begin{array}{l}\text { Área } \\
\left(\mathrm{Km}^{2}\right)\end{array}$} & \multirow{2}{*}{$\begin{array}{c}\text { Densidade } \\
\text { demográfica } \\
\left(\mathrm{hab} / \mathrm{Km}^{2}\right)\end{array}$} & \multicolumn{3}{|c|}{ População } \\
\hline & & & Urbana & Rural & Total \\
\hline Igrejinha & 136,8 & 231,4 & 30.190 & 1.470 & 31.660 \\
\hline Lindolfo Collor & 33,1 & 158,1 & 4287 & 940 & 5.227 \\
\hline Morro Reuter & 88,1 & 64,5 & 4841 & 835 & 5.676 \\
\hline Parobé & 109,0 & 472,4 & 48.633 & 2.869 & 51.502 \\
\hline $\begin{array}{l}\text { Presidente } \\
\text { Lucena }\end{array}$ & 49,4 & 50,3 & 1.511 & 973 & 2.484 \\
\hline Riozinho & 239,3 & 18,1 & 2.748 & 1.582 & 4.330 \\
\hline Rolante & 297,0 & 65,6 & 15.310 & 4.175 & 19.485 \\
\hline $\begin{array}{l}\text { Santa Maria } \\
\text { do Herval }\end{array}$ & 139,2 & 43,5 & 4.362 & 1.691 & 6.053 \\
\hline Taquara & 457,1 & 119,5 & 45.266 & 9.377 & 54.643 \\
\hline Três Coroas & 185,5 & 128,5 & 20.546 & 3.302 & 23.848 \\
\hline
\end{tabular}

Fonte: Morais (2012)

Além da indústria, o comércio varejista tem se desenvolvido desde a década de 1990, conforme Galvão (1999), derivado principalmente da atividade coureiro-calçadista, destacando-se lojas e comércios localizados às margens da rodovia que liga a microrregião Paranhana à região das Hortênsias, caracterizada por uma intensa atividade turística. Também cresceram empresas ligadas ao setor de papel e papelão, produtoras de embalagens para os calçados, além de indústrias ligadas ao setor metalmecânico, um importante apoio ao setor calçadista. Trata-se de um setor com efeito importante de multiplicação sobre os setores de plásticos, metais, químico, entre outros (MORAIS, 2012).

Como um dos principais polos do setor coureiro-calçadista da região Paranhana destaca-se a cidade de Igrejinha. No site da Prefeitura de Igrejinha (2016) verifica-se que em sua área total de 136,8 km², a natureza privilegia a cidade, contando com atrações naturais e culturais, conservando ambientes intactos, com núcleos de mata atlântica, possuindo seu vale cortado pelas águas do rio Paranhana, além de vários riachos e nascentes. Também possui diversas cascatas localizadas na zona rural.

Conforme o site do IBGE (2016), Igrejinha pertence à Microrregião Gramado-Canela e à Mesorregião Metropolitana de Porto Alegre. A localização do município é privilegiada, uma vez que se encontra no centro das três regiões mais populosas do estado: a região metropolitana de Porto Alegre, a região metropolitana de Caxias do Sul e a região Litoral Norte gaúcho, o que contribuiu para seu desenvolvimento, principalmente pela facilidade no escoamento de seus produtos. Seu principal acesso é pela RS-115, havendo também a RS-020 como alternativa. Como municípios limítrofes, apresentamse Taquara, Três Coroas, Parobé. Nova Hartz e Santa Maria do Herval. Atualmente, o núcleo urbano da cidade é composto por 15 bairros, havendo também 11 localidades, situadas na zona rural do município. De acordo com a FEE (2016), o município conta com 34.091 habitantes, com dados referentes a 2014, e um PIB per capita de $\mathrm{R} \$ 39.351,46$, referente ao mesmo período.

A região tem sua economia baseada na produção industrial, principalmente de calçados e confecções em couro e bebidas, preenchendo cerca de $50 \%$ de sua economia. Além da produção de calçados e componentes, há também a planta industrial da Brasil Kirin, uma das grandes empresas produtoras de cerveja e refrigerantes do Brasil (FEE, 2016). 
4 As feiras de produtores aproximando os consumidores urbanos dos agricultores familiares da região

A análise documental ocorreu através de pesquisa no acervo do Sindicato dos Trabalhadores Rurais e da Prefeitura Municipal de Igrejinha. Segundo ela, após análise realizada junto a sede da prefeitura de Igrejinha, a divisão territorial urbana foi formalizada através da Lei Municipal n41 de 1977, que criou inicialmente 7 bairros.

A mesma análise documental ainda permitiu averiguar como se sucedeu o desenvolvimento industrial na cidade, sendo que consta a informação de que por volta de 1930 foi fundada a primeira empresa de fabricação de calçados e artefatos de couros. A partir desse ano houve um grande aumento no número de empresas atuantes nesse ramo. As indústrias calçadistas de Igrejinha produzem cerca de 19 milhões de pares de calçados ao ano, focando principalmente o mercado de calçados femininos. Isso equivalente a mais de $2,5 \%$ de todo o volume de calçados fabricados no país, empregando cerca de 5,5 mil pessoas. Constatou-se que a cadeira coureirocalçadista representa mais de $53 \%$ no valor de retorno de ICMS ao município, utilizando dados de 2015. Além disso, na relação das 59 maiores empresas com valor adicionado de ICMS, figuram 41 empresas de produção de calçados e insumos ligados a esse setor. Tais dados demonstram a importância de toda produção coureiro-calçadista para a cidade de Igrejinha. Ainda, de acordo com os documentos disponibilizados pela prefeitura, a economia de Igrejinha compõe-se da seguinte forma (aproximadamente): agricultura - 1\%, indústria - 50\% e comércio/serviços - 49\%.

Em relação às características e dados dos agricultores as evidências encontradas são em relação aos bairros em que ocorrem as feiras dos produtores, que são Centro, XV de Novembro, Bom Pastor, Figueiras e Viaduto. Em análise documental realizada junto ao Sindicato dos Trabalhadores Rurais de Igrejinha foi possível conseguir um maior volume de dados e informações relativas aos produtores rurais da cidade, presentes em seus arquivos, compostos em sua maioria por informativos, projetos e memorandos.

Foi possível constatar que existem cerca de 300 famílias de agricultores na cidade de Igrejinha, com suas propriedades localizadas nos territórios do interior do município, como as localidades de Solitária Alta e Baixa, Voluntária Alta e Baixa, Rochedo, Serra Grande, Três Irmãos e Linha Caloni. Há variação entre o tamanho de suas propriedades, uma vez que vão de 5 a 30 hectares, mas, em média, as propriedades possuem nove hectares. Todos são considerados microprodutores de base familiar, sendo que a atividade predominante é a olericultura, porém, as atividades agrícolas apresentam variação conforme o microclima existente, mas os registros não apresentam maiores informações.

De acordo com os registros, a produção desses produtores feirantes é consumida dentro do próprio município, pois parte é comprada pela população em bairros da cidade, dentro das feiras de produtores, e a maior parcela é destinada à Secretaria de Educação de Igrejinha, onde os produtos são utilizados na merenda escolar nas escolas municipais, através do Programa Nacional de Alimentação Escolar (PNAE). Este programa realiza a transferência de recursos financeiros do Governo Federal, em caráter suplementar, ao município para a aquisição de gêneros alimentícios dos agricultores familiares, destinando-os à merenda escolar e garantindo renda aos produtores rurais do município. Também, constatou-se a permanência das famílias no campo, uma vez que não houve redução no número de associados ao Sindicato nos últimos quatro anos.

Em relação às feiras de produtores, foi possível constatar que 25 famílias de produtores do município são feirantes, em cinco bairros da cidade, procurando-se escalonar o trabalho para melhor atender toda a população. O número de famílias e escalas das feiras podem ser verificados no Quadro 2 .

O projeto de feiras de produtores nasceu da necessidade de o agricultor ter que agregar valor ao 
seu produto para gerar maior renda. Foi uma iniciativa conjunta do Sindicato dos Trabalhadores Rurais, Prefeitura Municipal, EMATER e dos próprios agricultores, com o objetivo de se ter uma alternativa de comercialização de seus produtos. O Sindicato presta apoio constante em toda a cadeia, desde a organização das feiras, busca de melhorias nas estruturas destas, até a comercialização. Já a prefeitura presta apoio através da compra de alimentos para merenda escolar e da disponibilização de espaços e estrutura física fixa para a realização das feiras dos agricultores familiares. Os documentos encontrados atestam que as feiras mantêm a mesma dinâmica desde a sua criação, em meados da década de 1990, contando praticamente com o mesmo número de famílias responsáveis. Porém, há um planejamento do sindicato para ampliar o número de feiras, atendendo assim a uma maior parcela da população, mas ainda são necessárias definições em relação aos bairros em que estarão localizadas.

\section{Quadro 2 - Bairros, número de famílias e dias de feiras de produtores}

\begin{tabular}{|l|l|l|}
\hline Bairro & $\begin{array}{l}\text { № famílias } \\
\text { feirantes }\end{array}$ & Dias de feira \\
\hline Centro & 14 & $\begin{array}{l}\text { Terças e quintas-feiras, } \\
\text { sábados }\end{array}$ \\
\hline Figueiras & 3 & Quartas-feiras, sábados \\
\hline $\begin{array}{l}\text { XV de } \\
\text { Novembro }\end{array}$ & 3 & $\begin{array}{l}\text { Terças e quintas-feiras, } \\
\text { sábados }\end{array}$ \\
\hline $\begin{array}{l}\text { Bom } \\
\text { Pastor }\end{array}$ & 3 & $\begin{array}{l}\text { Segundas e sextas- } \\
\text { feiras, sábados }\end{array}$ \\
\hline Viaduto & 2 & Terças-feiras, sábados \\
\hline
\end{tabular}

Fonte: elaborado pelos autores, com dados da Prefeitura Municipal de Igrejinha (2016).

Após, passou-se à aplicação de questionário aos agricultores participantes de feiras na cidade de Igrejinha. Os entrevistados relataram que a maioria dos chefes de família tem idade variando entre 31 e 61 anos de idade, com $84 \%$ dos entrevistados nesta faixa etária e 16\% assinalaram a resposta acima de 61 anos de idade. Foi possível identificar que as famílias entrevistadas possuem entre 2 a 5 integrantes, sendo que a maioria, com $40 \%$ do total, corresponde a 4 integrantes. Com relação ao tamanho da propriedade dos entrevistados, as respostas mostram que um terço dos entrevistados possuem propriedade com menos de 3 hectares e $47 \%$ deles responderam que suas propriedades possuem acima de 13 hectares. Quanto à localização das propriedades dos entrevistados, verificou-se que 35\% delas se localizam em Serra Grande, interior de Igrejinha. Em torno de $70 \%$ dos agricultores familiares entrevistados possuem renda familiar mensal entre 2 e 3 salários-mínimos, enquanto que os demais têm renda mensal acima de 3 salários-mínimos.

$\mathrm{Na}$ região do Corede Paranhana-Encosta da Serra há uma população rural em torno de 27.200 habitantes, $15,3 \%$ da população total, formada basicamente por agricultores familiares que buscam alternativas de geração de renda e de ocupações (Quadro 1). Estima-se que essa população corresponde a aproximadamente 8 mil famílias que poderiam se dedicar à produção de alimentos, in natura ou processados por agroindústrias familiares ou cooperativas, que seriam destinados para quase 180 mil potenciais consumidores de bens e serviços agroalimentares e turísticos, que atualmente vivem nos centros urbanos da região do Corede, grande parte deles empregados do setor calçadista.

Buscou-se, também, identificar os principais produtos agroalimentares produzidos pelos feirantes entrevistados, mas não necessariamente comercializados nessas feiras. Todos os agricultores produzem mais de um produto, com destaque para a batata, cenoura, feijão, repolho, brócolis, milho e aipim, produzidos por metade dos entrevistados. Mas há também a produção de frutas em geral e a pecuária bovina, de corte e leiteira. Verificou-se a predominância de sistemas de produção de base familiar, com propriedades com uma área média de 9 hectares e com uma grande variedade de espécies cultivadas, mas, como se descreveu acima, com predominância da olericultura.

Todos os entrevistados responderam que praticam outras formas de comercialização, além da feira do produtor do município de Igrejinha e que o 
desemprego e a crise pela qual passa o setor calçadista levaram a uma diminuição da sua produção, assim como também houve diminuição das vendas em razão do fechamento das empresas de calçados e o consequente desemprego teve reflexos sobre a demanda de produtos agroalimentares, fazendo com que diminuíssem o volume e o tipo de produtos comercializados. Todos também disseram que nos últimos 6 meses houve uma redução da renda familiar, em razão de dificuldades nos negócios e que a crise local provocou uma redução da sua produção, devido a uma maior dificuldade nas vendas. Atualmente, as maiores dificuldades enfrentadas pelos agricultores familiares entrevistados são a redução das vendas (40\%) e o escoamento da produção (30\%).

Os agricultores familiares vêm adotando algumas estratégias para contornar as dificuldades relacionados com a nova realidade dos mercados consumidores locais, como reflexo das mudanças nos mercados de trabalho locais. Entre as principais estratégias estão os investimentos em outras culturas, produção com maior qualidade, redução da produção para evitar sobras e a redução de preços. Todos apontaram mais de uma alternativa para esta superação, com destaque para a diminuição da produção para evitar sobras e a redução de preços para ampliar a venda e tornar-se competitivo. Talvez uma política de incentivo a atividades agregadoras de valor como a agroindustrialização de parte da produção, atualmente vendida in natura, para evitar perdas ou sobras e adoção de atividades complementares agropecuárias ou do setor de serviços. Como exemplo deste último, pode ser citado o turismo rural, com ou sem a venda permanente de produtos artesanais ou processados por uma agroindústria familiar.

Tendo em vista que a produção desses agricultores familiares vem sendo utilizada também como merenda escolar, contempla-se a sugestão de Abramovay e Veiga (1999), quando afirmam que a agricultura familiar pode oferecer segurança alimentar à população. A própria existência das feiras e a possibilidade de ampliação do atendimento à comunidade municipal urbana podem sugerir que a redução do número de empregos e as dificuldades do setor calçadista, principal segmento da cidade e região, impactam os agricultores de Igrejinha. Mas este impacto é amenizado pela importância dada pela comunidade à produção advinda das propriedades rurais do município. Tal suposição pode encontrar amparo em Veiga (2006) e Favareto (2006) quando estes afirmam que há tendência de valorização do espaço rural nos dias de hoje, por meio de uma nova concepção do espaço rural.

Enfim, não se ampliou mais o debate sobre as novas configurações urbano-industrial, no sentido da discussão sobre a penetração das relações capitalistas de produção nas grandes metrópoles, porque a realidade da região onde Igrejinha está inserida é de cidades médias e pequenas e com áreas rurais com uma população relativamente importante. No entanto, verifica-se uma expansão dessas relações, com uma certa tendência à predominância da preocupação com os problemas urbanos-industriais em detrimento aos problemas socioeconômicos do rural-agrícola.

\section{Considerações finais}

A presente pesquisa teve como principal objetivo analisar os efeitos das mudanças nas organizações produtivas urbanas sobre a produção e comercialização de produtos agroalimentares e sobre o nível de renda dos agricultores familiares do município Igrejinha. Finalizada a primeira parte da coleta de dados, os resultados são parciais e ainda não contemplam todos os objetivos, uma vez que a pesquisa ainda se encontra em curso.

A diminuição de renda nos últimos meses e as dificuldades de escoamento da produção, o que leva consequentemente a diminuição do plantio, também são impactos determinantes protagonizados pelo setor industrial sobre o meio rural. Por outro lado, a diversificação da produção merece ser frisada, predominando, tanto no levantamento documental como nos dados coletados através do questionário, a 
olericultura como principal alternativa de produção agrícola.

Os dados angariados através da aplicação dos questionários permitiram constatar que o meio urbano tem influência direta sobre a produção e a renda dos agricultores familiares do município de Igrejinha, uma vez que todos citam os efeitos sentidos em suas atividades em decorrência do desemprego e da crise nas empresas calçadistas da cidade e região. Além da continuidade das tradicionais vendas nas feiras de produtores, esses agricultores têm elaborado diferentes estratégias para conseguirem se manter nas suas atividades e no meio rural. Uma das alternativas citadas para isso tem sido a comercialização em outros canais, como por exemplo, aproveitando cadeias curtas, denominadas assim devido à proximidade entre o produtor e o consumidor, como a venda direta à prefeitura, para distribuição como merenda escolar, através do Programa nacional de Alimentação Escolar (PNAE), constatado pelo levantamento na pesquisa documental.

Contudo, visto a existência de poucos documentos relacionados ao processo e volume de comercialização dos produtores feirantes, procurarse-á coletar tais dados empiricamente, através da aplicação dos novos questionários, com maior detalhamento, na segunda fase da pesquisa. Esperase que, com tais informações, seja possível contemplar, de forma mais detalhada, os objetivos de pesquisa estipulados, avaliando in loco os impactos urbanos sobre a produção e comercialização dos agricultores familiares de Igrejinha.

\section{Referências}

ABRAMOVAY, R.; VEIGA, J. E. Novas Instituições para o Desenvolvimento Rural: o caso do Programa Nacional de Fortalecimento da Agricultura Familiar (PRONAF). IPEA. Texto para discussão n0 641/Convênio FIPE/IPEA 07/97. Brasília, 1999. Disponível em <http://repositorio.ipea.gov.br/bitstream/11058/26 17/1/td_0641.pdf>. Acesso em: 09 set 2016. INDUSTRIAIS DE CALÇADO, COMPONENTES,
ARTIGOS DE PELE E SEUS SUCEDÂNEOS, Disponível em $<$ http://www.apiccaps.pt/c/document_library/get_f ile?uuid=7d10300e-b8e0-40ae-b9be246e4327714c\&groupld=10136>. Acesso em: 19 set 2016 .

CALANDRO, M. L.; CAMPOS, S. H.. Arranjo Produtivo Local calçadista Sinos-Paranhana. Relatório I. Porto Alegre: FEE, 2013. Relatório do Projeto Estudo de Aglomerações Industriais e Agroindustriais no RS. Disponível em: <http://www.fee.rs.gov.br/publicacoes/relatorios/ >. Acesso em 09 set 2016.

CARNEIRO, M. J. Política pública e agricultura familiar: uma leitura do Pronaf. Estudos Sociedade e Agricultura, N. 8, Rio de Janeiro, $1997 . \quad$ Disponível em $<$ http://bibliotecavirtual.clacso.org.ar/ar/libros/bra sil/cpda/estudos/oito/carneiro8.htm> Acesso em 12 set 2016 .

COSTA, V. S. et al. Análise de custos a partir da cadeia do valor do leite e seus derivados na região Seridó do Rio Grande do Norte. Revista Ambiente Contábil, Natal, v.7, n.1, jan-jun., 2015. Disponível

em $<$ http://periodicos.ufrn.br/ambiente/article/view/56 02/5060> . Acesso em 25 jun. 2016.

COUTO, A. T. Agricultura familiar e produção leiteira: análise do sector cooperativo leiteiro da região norte de Portugal e do setor familiar produtor de leite no sul do Brasil. Boletim Goiano de Geografia. Goiânia, v.23, n.2, jul-dez, 2003. Disponível em $<$ https://revistas.ufg.br/bgg/article/view/4178/367 2>. Acesso em 23 jun. 2016.

DENARDI, R. A. Agricultura familiar e políticas públicas: alguns dilemas e desafios para o desenvolvimento rural sustentável. Agroecologia e Desenvolvimento Rural Sustentável. Porto Alegre, v.2, n.3, jul/set 2001. Disponível em <http://www.emater.tche.br/docs/agroeco/revista/ ano2_n3/revista_agroecologia_ano2_num3_part e12_artigo.pdf>. Acesso em 09 set 2016.

EMPRESA BRASILEIRA DE PESQUISA AGROPECUÁRIA - EMBRAPA. Disponível em $<$ https://www.embrapa.br/embrapa-no-anointernacional-da-agricultura-familiar $>$ Acesso em 24 jun 2016.

FAVARETO, A. Paradigmas do desenvolvimento rural em questão. Tese de Doutorado - Programa de Pós-Graduação em Ciência Ambiental, 2006.

FUNDAÇÃO DE ECONOMIA E ESTATÍSTICA (FEE). Disponível em <http://www.fee.tche.br>. Acesso em: 13 de abril de 2016.

GALVÃO, C. A. Sistemas Industriais Localizados: O Vale do Paranhana - Complexo Calçadista do Rio Grande do Sul. Texto para discussão № 
617. Textos para Discussão IPEA. Brasília, 1999. Disponível em <http://ipea.gov.br/agencia/images/stories/PDFs/ TDs/td_0617.pdf> Acesso em 13 de abril de 2016.

GOBBI, W; A. O; PESSOA, V. L. S. A pecuária leiteira e a agricultura familiar em Ituiutaba (MG): as transformações na comunidade da Canoa. Geo UERJ, Rio de Janeiro, ano 11, v.1, n.19, 1은 semestre, p. 79-110, 2009. Disponível em $<\mathrm{http}: / /$ www.e-

publicacoes.uerj.br/index.php/geouerj/article/view /1405/1195.>. Acesso em 22 jun. 2016.

INSTITUTO BRASILEIRO DE GEOGRAFIA E ESTATÍSTICA - IBGE. Disponível em <www.ibge.gov.br> Acesso em 20 de abril de 2016.

MATTE JR, A.A.; MORAIS, R. T.; SELLITO, M. A. Internacionalização de uma empresa calçadista por lojas fidelizadas: estudo de caso. Revista Geintec, São Cristóvão, V. 6, N.2, p. 2991-3004. Disponível em <http://www.revistageintec.net/portal/index.php/r evista/article/view/675/649>. Acesso em 19 set 2016.

MATTEI, L. O papel e a importância da agricultura familiar no desenvolvimento rural brasileiro contemporâneo. Rev. Econ. NE, Fortaleza, v. 45, p. 71-79, 2014 (suplemento especial). Disponível em

<http://www.bnb.gov.br/documents/80223/20536 5/ren_2014_6_lauro_v2.pdf/72b45117-194f-

$4 a 4 b-8 b 1 d-\overline{5} 8 \bar{b} 1 f 893 a f 40>$. Acesso em 09 set 2016.

MORAIS, R. T. Gestão Democrática como instrumento de planejamento estratégico regional: Estudo das experiências no Conselho Regional de Desenvolvimento ParanhanaEncosta da Serra. Programa de Pós-Graduação em Desenvolvimento Regional - Doutorado, Universidade de Santa Cruz do Sul, 2012.

NETO, B. S.; BASSO, D. A produção de leite como estratégia de desenvolvimento para o Rio Grande do Sul. Desenvolvimento em questão,3(5), 53-72. 2005. Disponível em <http://www.redalyc.org/pdf/752/75230504.pdf > Acesso em 22 jun 2016.

PORTAL MUNICIPAL - FAMURS. Disponível em <http://www.portalmunicipal.org.br/entidades/fam urs/municipio/historia. asp?ildEnt=5523\&ildMun= 100143188 > Acesso em 13 de abril de 2016.

PREFEITURA MUNICIPAL DE IGREJINHA. História. Disponível <http://www.igrejinha.rs.gov.br/p.asp?i=6\&c=Cid ade $>$ Acesso em 13 de abril de 2016.

SCHNEIDER, S. A pluriatividade como estratégia de reprodução social da agricultura familiar no Sul do Brasil. Estudos Sociedade e Agricultura, N. 16, p. 164-184, Rio de Janeiro, 2001. Disponível em <http://bibliotecavirtual.clacso.org.ar/ar/libros/bra sil/cpda/estudos/dezesseis/schneid16.htm> Acesso em 12 set 2016.

SCHNEIDER, S. Teoria Social, agricultura familiar e pluriatividade. Revista Brasileira de Ciências Sociais, vol. 18, N. 51, São Paulo, 2003. Disponível em <http://www.scielo.br/pdf/rbcsoc/v18n51/15988.p df $>$ Acesso em 12 set 2016.

WANDERLEY, M. N. B. A ruralidade no Brasil moderno; por um pacto social pelo desenvolvimento rural. In: GIARRACCA, Norma (org.). ¿Una nueva ruralidad en América Latina? Buenos Aires: CLACSO, 2001, p. 31 - 44.

VEIGA, J. E. Mudanças nas relações entre espaços rurais e urbanos. Revista Brasileira de Gestão e Desenvolvimento Regional, V. 3, N. 1, p. 123149, Taubaté, 2006. Disponível em <http://www.rbgdr.net/revista/index.php/rbgdr/arti cle/view/22/19>. Acesso em 09 set 2016. 